\title{
Analisis Sajian Buku Ajar Fisika SMA Kelas X Semester 1 Terkait Komponen Science, Technology, Engineering, Mathematics (STEM)
}

\author{
Laura Aliyah Agnezi, Nyswatul Khair, Sinta Yolanda \\ Program Studi Magister Pendidikan Fisika Pasca Sarjana Universitas Padang \\ lauraaliyahagnezi@gmail.com \\ nyswatulkhair510@gmail.com \\ sintayolanda11@gmail.com
}

\begin{abstract}
An important problem in the 21st century is the integration of information and communication technology in learning. Because teachers and students must be prepared to keep abreast of increasingly sophisticated times. STEM is a learning that integrates science (science), technology (technology), engineering (engineering), and mathematics (mathematics). STEM provides learning through the process of solving problems in everyday life in order to enhance students' creative abilities. STEM learning aims to improve the ability of students to compete with the surrounding environment and globally, both in science and able to innovate technological products. Currently there are many textbooks in circulation with various publishers. For this reason, it is necessary to find out whether the outstanding textbooks have been able to facilitate the implementation of the STEM approach in learning. The solution to this problem is to analyze the extent to which the textbook meets the STEM component. This type of research is a descriptive research with a qualitative approach. The population of data in this research were all physics textbooks for class $X$ semester 1 high school. The samples in this research were five books used in learning physics in class $X$ semester 1 high school. The data in this research were taken using a research instrument which had 4 components which were elaborated into 19 assessment items and data collection techniques used are through observation. The results of this research indicate that the average suitability obtained for each book that is in textbook 1 has a value of 88 with a category in accordance with the STEM component. In textbook 2 has a value of 85 with a category in accordance with the STEM component. In textbook 3 with a value of 72 with categories according to the STEM component. Textbook 4 with a value of 77 with categories according to the STEM component. Finally in textbook 5 with a value of 85 with a category very much in accordance with the STEM component.
\end{abstract}

Keywords : Learning textbooks, Science, Technology, Engineering, Mathematics

This is an open access article distributed under the Creative Commons 4.0 Attribution License, which permits unrestricted use, distribution, and eproduction in any medium, provided the original work is properly cited. @2019 by author and Universitas Negeri Padang.

\section{PENDAHULUAN}

Permasalahan penting di abad ke-21 yaitu mengintegrasikan teknologi informasi dan komunikasi dalam pembelajaran. Guru dan siswa harus siap mengikuti perkembangan zaman yang semakin canggih. Guru harus kreatif, aktif dan inovatif dalam penggunaan teknologi dalam pembelajaran sehingga tercipta pembelajaran yang lebih aktif kreatif dan menyenangkan (Rusman, 2017).

Guru memiliki peran penting dalam mempersiapkan siswanya untuk kehidupan masa depan mereka dan karir, karena mereka harus bergulat dengan kehidupan nyata masalah yang menarik dan relevan. Pembelajaran STEM proyek dapat menuntut siswa untuk aktif dalam mempelajari konsep-konsep penting melalui proyek kreatif dan inovatif. Keterlibatan mereka dalam proses pemecahan masalah membangun budaya pertanyaan, di mana pusat dari proses pembelajaran adalah menanyakan dan menjawab pertanyaan mereka sendiri (Beers, 2011).

STEM merupakan proses pembelajaran yang memadukan science (sains), technology (teknologi), engineering (rekayasa), serta mathematics (matematika). Proses pembelajaran STEM bertujuan untuk meningkatkan kemampu an kreativitas siswa melalui proses pemecahan masalah yang berkaitan dengan materi dalam kehidupan sehari-hari. Kemampuan abad 21 
merupakan kemampuan belajar dan memberikan inovasi antara lain; berpikir kritis, berpikir kreatif, inovatif, mampu berkolaborasi, serta keterampilan dalam menggunakan media, teknologi, informasi, dan komunikasi (TIK) (Winarni, Zubaidah, \& H., 2016)

Pembelajaran STEM bertujuan dalam meningkatkan kemampuan siswa agar dapat bersaing dengan lingkungan sekitar maupun secara global, baik dalam sains dan mampu menginovasikan produk teknologi (Utami et al., 2017). Pembelajaran yang menggunakan aspekaspek STEM memberikan kesempatan kepada siswa untuk lebih memahami konsep fisika. Pembelajaran dipadukan dengan teknologi, rekayasa dan matematika melalui kegiatan praktikum, diskusi, dan pemberian tugas proyek. Pengetahuan siswa akan lebih dalam jika melakukan pembuatan proyek yang berintegrasi dengan sains, teknologi, dan matematika. Pembuatan proyek terdapat pada aktivitas rekayasa pada pembelajaran yang berbasis STEM. Aspek-aspek pada STEM juga dileng kapi dengan permasalahan yang disajikan beser ta prosedur praktikum (Pangesti et al., 2017).

Pada pembelajaran STEM terdapat komponen sains. Konsep komponen sains merupakan pembelajaran yang digunakan untuk memahami fenomena alam dan perubahan yang terjadi yang diakibatkan oleh kegiatan manusia. (Asrizal \& Dewi, 2018). Selain itu, komponen sains juga melatih siswa untuk memiliki skills dalam ikut serta pada pengambilan pendapat dalam proses pembelajaran

STEM memiliki komponen teknologi. Komponen teknologi erat kaitannya dengan perkembangan era digital pada saat ini. Era digital dikenal dengan adanya jaringan internet, khususnya teknologi informasi komputer. Pengguna teknologi memiliki kemampuan untuk menemukan, mengakses, menggunakan, dan mengeva luasi berbagai informasi yang terdapat pada teknologi digital dan jaringan internet (Asrizal et al., 2018).

Media pembelajaran yang digunakan dalam pembelajaran merupakan berbagai kompo nen yang ada pada lingkungan sekitar sehingga dapat merangsang kemauan belajar siswa. Keberadaan media pembelajaran sangat penting dalam proses belajar mengajar. Hal itu dikarenakan, pengalaman belajar tidak semua dapat diperoleh secara langsung. Keberadaan media bertujuan untuk memberikan pembe lajaran atau pengetahuan agar mudah dipahami serta konkret (Festiyed, 2018).

Penggunaan kegiatan penyelidikan memberikan kesempatan kepada siswa untuk mengembangkan kemampuan kinerja. Kegiatan penyelidikan dilakukan sampai diperolehnya kesimpulan serta mengomunikasikan hasil yang diperoleh. Kegiatan ini juga bertujuan untuk mengembangkan keterampilan sosial sehingga dapat mendukung berkembangnya kemampuan kognitif siswa (Festiyed \& Murtiani, 2013). Hal ini diperkuat oleh penelitian Agustina et al. (2017) yang menunjukkan bahwa hasil pembela jaran STEM mampu meningkatkan kemampuan variabel kontrol siswa.

Kegiatan penyelidikan yang dilakukan dapat berupa kegiatan praktikum. Kegiatan praktikum ada dua macam berdasarkan media nya yaitu pelaksanaan pratikum secara real (nyata) dan pelaksanaan praktikum dalam bentuk virtual atau istilah lainnya virtual laboratory. Laboratorium virtual mampu mengatasi kesulitan guru dalam merancang dan melaksanakan praktikum. Dengan laboratorium virtual dapat meminimalisir biaya yang digunakan dalam pengadaan alat dan bahan untuk pelaksanaan praktikum (Masril et al., 2018).

STEM memiliki komponen matematika. Komponen matematika pada STEM dijelaskan bahwa pembelajaran akan mnghasilkan siswa yang terampil dalam menyelesaikan permasalahan. Penyelesaian masalah terlebih dahulu harus dianalisis, memberikan alasan, kemudian meng komunikasikan hasil atau ide sacara efektif. Pembelajaran STEM juga melatih siswa untuk mencari solusi dalam berbagai permasalahan matematika dalam aplikasinya.

Permasalahan atau soal yang diberikan kepada siswa pada pembelajaran STEM merupa kan soal yang memiliki tingkat kesulitan yang cukup tinggi atau high order thinking skills (HOTS). Soal yang diberikan menuntut siswa untuk menganalisis soal terlebih daluhu. Dengan demikian, siswa dapat melatih pola pikir mereka dengan soal HOTS. Kemampuan berpikir kritis dapat membantu siswa menampilkan ide-ide atau gagasan baru dalam berbagai permasalahan dalam kehidupan sehari-hari.

Interaksi merupakan aspek penting dalam pembelajaran, oleh karena itu kegiatan pembelajaran tidak dapat terlepas dari interaksi. Interaksi yang terjadi dalam pembelajaran bisa 
saja terjadi antara guru dan siswa, siswa dan siswa, maupun siswa dan lingkungan sekitar. Interaksi dalam pembelajaran menuntut adanya perubahan sikap atau tingkah laku menjadi lebih baik. Interaksi dalam pembelajaran dapat terwujud jika didukung dengan keadaan pembelajaran yang memiliki makna, menyenangkan, kreatif, dinamis, dan dialogis (Budiharti \& Devi, 2016).

Pembelajaran berbasis STEM bertujuan untuk menyiapkan siswa dalam memenuhi kemampuan abad 21. Untuk mendukung pembela jaran berbasis STEM diperlukan bahan ajar yang mampu memfasilitasi terlaksananya pembelajar an tersebut. Setelah mengkaji penelitian terda hulu tidak ditemukan penelitian yang meng analisis buku ajar fisika SMA kelas $\mathrm{X}$ semester 1 terkait dengan pembelajaran STEM.

Saat ini telah banyak buku ajar fisika SMA kelas $\mathrm{X}$ semester 1 yang beredar dengan bermacam penerbit. Untuk itu perlu dicari tahu apakah buku ajar yang beredar tersebut sudah mampu memfasilitasi terlaksananya pendekatan STEM dalam pembelajaran. Solusi dari masalah ini adalah melakukan analisis sejauh mana buku ajar telah memenuhi komponen STEM. Tujuan dari penelitian ini adalah untuk mengetahui apakah sajian buku ajar fisika SMA kelas $\mathrm{X}$ semester 1 yang banyak digunakan saat ini sudah memfasilitasi keterlaksanaan pendekatan STEM dalam pembelajaran.

\section{METODE PENELITIAN}

Jenis penelitian yang dilakukan adalah penelitian deskriptif. Penelitian ini merupakan penelitian dasar yang dilakukan. Penelitian ini bertujuan mendeskripsikan atau menyampaikan kejadian yang bersifat natural maupun suatu kejadian yang direkayasa. Penelitian deskriptif dilakukan dengan tujuan menggambarkan fakta secara sistematis dan karakteristik objek yang akan diteliti secara tepat (Sukardi, 2004). Pada penelitian ini peneliti berusaha untuk melapor kan keadaan objek yang diteliti sesuai dengan apa adanya.

Penelitan deskriptif yang dilakukan yaitu menggambarkan atau mendeskripsikan komponen STEM yang terdapat dalam buku ajar fisika SMA kelas $\mathrm{X}$ semester 1. Populasi pada penelitian ini yaitu seluruh buku fisika SMA kelas X semester 1. Teknik pengambilan sampel yang digunakan yaitu nonprobability sampel, dengan jenis purposive sampling dimana sampel yang diambil dengan tujuan dan pertimbangan tertentu. Pada penelitian ini terdapat lima buku yang diambil sebagai sampel penelitian. Kelima buku ini yang memiliki isi materi yang mendekati dengan tuntutan kurikulum 2013 untuk materi fisika SMA kelas X semester 1. Di dalam buku ajar tersebut terdapat enam materi yang akan dianalisis pada setiap buku. Materi tersebut yaitu materi pengukuran, vektor, gerak lurus, gerak parabola dan gerak melingkar.

Alat yang dipakai dalam mengukur suatu kejadian yang akan diteliti disebut instrumen penelitian (Sugiyono, 2017). Instrumen peneliti an yang digunakan adalah lembar analisis berbentuk pernyataan yang mencakup empat komponen STEM yaitu science, technology, engginering, mathemathic pada pokok materi SMA kelas $\mathrm{X}$ semester 1. Instrumen yang digunakan memuat 19 butir pernyataan yang terkait masing-masing komponen STEM.

Teknik pengumpulan data yang digunakan dalam penelitian ini yaitu dengan cara observasi. Peneliti mengobservasi masingmasing-masing materi di setiap buku untuk melihat apakah pada setiap materi tersebut mengandung komponen STEM atau tidak. Data yang didapatkan dalam penelitian ini menggunakan lembar instrumen analisis buku ajar fisika SMA kelas $\mathrm{X}$ semester 1 berbasis STEM. Setiap butir instrumen diberikan centang ada atau tidaknya butir instrumen yang terdapat pada buku ajar fisika. Jika terdapat komponen STEM pada buku ajar maka diberi centang, jika tidak ditemukan komponen STEM pada buku ajar diberikan silang pada kondisi tersebut.

Data yang dikumpulkan melalui instrumen yang sesuai dianalisis dengan menggunakan teknik analisis tertentu. Teknik analisis data yang dipakai merupakan teknik analisa isi (content analysis). Teknik analisis isi merupakan teknik yang menganalisa isi (content) dari data tertulis. Teknik analisis ini merupakan teknik yang dikerjakan dengan sesuai urutan pada catatan ataupun dokumen yang dijadikan sebagai sumber. Dokumen dapat berupa teks tertulis, karya tulis, gambar maupun foto (Yusuf, 2013). Pada penelitian ini dokumen yang digunakan berupa teks tertulis (buku ajar).

Proses analisis data yang dilakukan yaitu menganalisis buku ajar fisika SMA kelas $\mathrm{X}$ semester 1 terkait komponen STEM. Lalu kriteria penskoran pada aspek yang dianalisis meng-gunakan skor 1 dan 0 . Dimana skor 1 
menyatakan "ada" dan skor 0 menyatakan "tidak ada". Langkah selanjutnya yaitu menjumlahkan skor setiap komponen STEM pada masingmasing buku ajar lalu skor dikonversi ke dalam nilai rentang 0-100. Langkah terakhir yaitu meng-interpertasikan kesesuaian buku ajar fisika SMA kelas $\mathrm{X}$ semester 1 terkait komponen STEM. Untuk penyajian data dalam statistik deskriptif pada penelitian ini yaitu data disajikan dalam bentuk grafik.

\section{HASIL DAN PEMBAHASAN}

\section{Hasil Penelitian}

Analisis buku ajar Fisika SMA Kelas X Semester 1 berbasis STEM terdiri atas empat komponen yang dijabarkan menjadi 19 butir penilaian. Penilaian dilakukan dengan melihat adanya komponen STEM yaitu sains, teknologi, rekayasa dan matematika yang terdapat di dalam buku ajar Fisika SMA Kelas X Semester 1. Analisis dilakukan untuk mengetahui sejauh mana buku ajar Fisika yang dipakai memuat komponen STEM dalam pembelajaran.

Materi dari buku ajar yang akan dianalisis yaitu materi pokok Fisika SMA kelas X Semester 1 pada Kurikulum 2013. Materi yang dianalisis yaitu materi pengukuran, vektor, gerak lurus, gerak parabola dan gerak melingkar. Hasil pengolahan data keterpenuhan komponen STEM pada buku yang dianalisis dapat dilihat pada grafik dibawah ini.

Untuk komponen STEM yang pertama yaitu sains. Sains dapat diartikan sebagai kemampuan dalam menggunakan pengetahuan ilmiah dan kemampuan dalam berpartisipasi dalam mengambil keputusan. Dengan adanya pendidikan sains diharapkan siswa mampu mempelajari alam sekitar dan dapat menerapkannya dalam kehidupan sehari-hari (Permanasari, 2016). Pada komponen sains terdapat lima butir pernyataan. Hasil penilaian komponen sains dapat dilihat pada Gambar 1

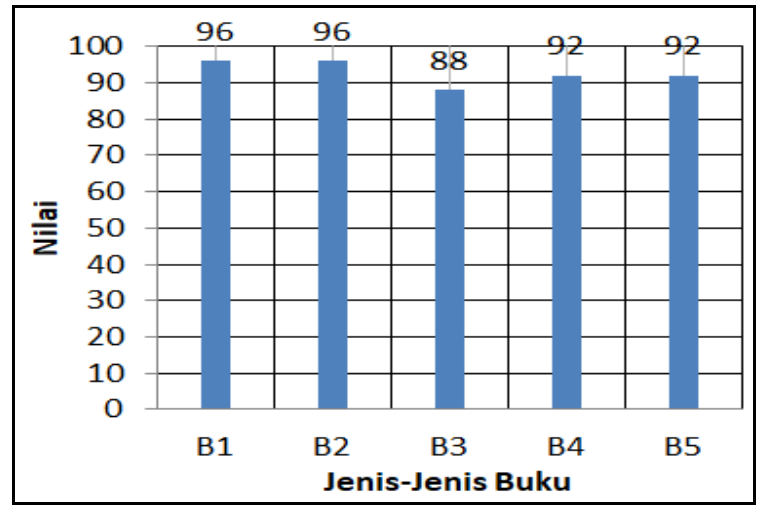

Gambar 1 Hasil Penilaian Komponen Sains

Pada Gambar 1 terlihat bahwa ada tiga variasi nilai pada penilaian komponen sains untuk kelima buku yaitu 96, 92 dan 88. Pada buku 1 memiliki komponen sains sebesar 96. Begitu juga buku 2 memiliki komponen sains sebesar 96. Pada buku 3 memiliki nilai komponen sains sebesar 88. Buku 4 memiliki nilai komponen sains sebesar 92 dan terakhir buku 5 memiliki nilai sebesar 92. Pada hasil penilaian komponen sains buku 1 memiliki nilai yang paling tinggi, dan secara keseluruhan semua buku telah memenuhi dengan baik komponen sains untuk semua materi fisika SMA kelas X pada semester 1.

Komponen kedua yaitu teknologi. Teknologi merupakan sebuah pengetahuan bagaimana siswa dapat mengetahui perkembangan teknologi dan bisa menerapkan teknologi tersebut di dalam pembelajaran. Salah satu contoh teknologi dapat diaplikasikan dalam pembelajaran seperti mengaitkan materi kedalam situs web internet, penggunaan software dalam pembelajaran (Stohlman et al., 2012). Contoh penggunaan software dalam pembelajaran yaitu pemakaian google map pada materi gerak lurus. Pada komponen teknologi terdapat lima komponen pernyataan. Hasil penilaian komponen teknologi dapat dideskripsikan melalui Gambar 2. 


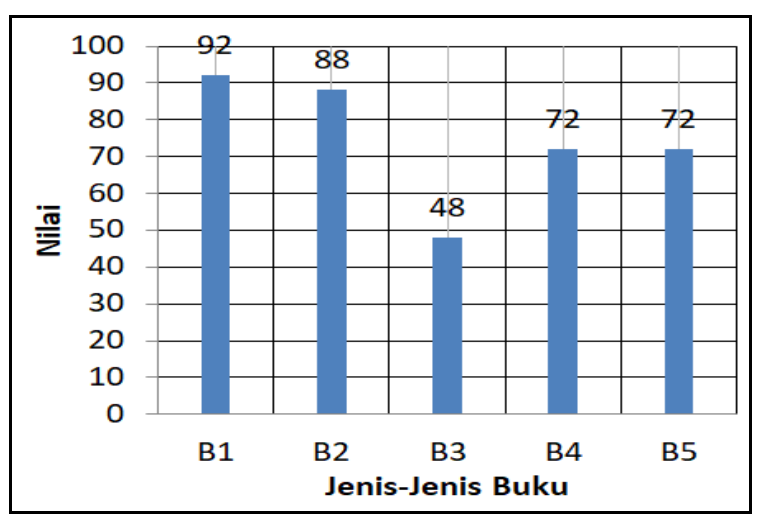

Gambar 2 Hasil Penilaian Komponen Teknologi

Pada Gambar 2 terlihat bahwa ada empat variasi nilai pada penilaian komponen teknologi untuk kelima buku ajar yaitu 92, 88, 72, dan 48. Pada buku 1 memiliki komponen teknologi sebesar 92. Pada buku 2 memiliki nilai sebesar 88. Buku 3 memiliki nilai komponen teknologi sebesar 48. Lalu pada buku 4 memiliki nilai sebesar 72 , begitu juga buku 5 memiliki nilai sebesar 72. Buku ajar yang memiliki komponen teknologi paling tinggi yaitu buku 1 sebesar 92, sedangkan buku ajar yang memiliki komponen teknologi yang rendah adalah buku 3 .

Untuk komponen ketiga yaitu rekayasa. Rekayasa dapat menjadi jembatan penghubung antara ilmu sains dengan matematika. Rekayasa juga dapat mengaplikasikan teknologi di dalam pelaksanaan pembelajaran. Melalui rekayasa (praktik) siswa dapat mengembangkan kemampuan dan berpartisipasi aktif dalam proses pembelajaran (Shahali et al., 2017). Pelaksanaan praktikum di dalam pembelajaran dapat dilaksanakan dengan secara nyata maupun secara virtual. Pada komponen rekayasa terdapat empat komponen pernyataan. Hasil penilaian komponen rekayasa dikemukakan oleh Gambar 3.

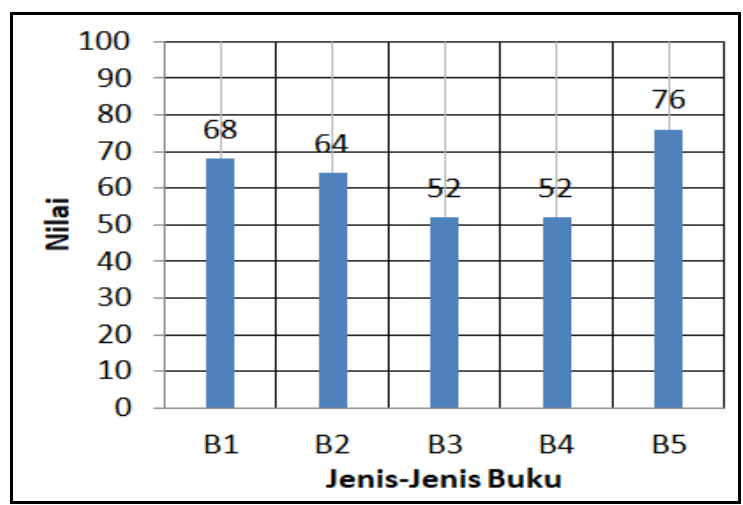

Gambar 3 Hasil Penilaian Komponen Rekayasa

Pada Gambar 3 dapat dijelaskan bahwa buku 1 memiliki nilai komponen rekayasa sebesar 68. Buku 2 memiliki nilai komponen rekayasa sebesar 52. Lalu buku 3 memiliki nilai komponen rekayasa sebesar 68. Pada buku 4 memiliki nilai sebesar 52. Terakhir buku 5 memiliki nilai sebesar 76. Pada hasil penilaian komponen rekayasa yang terdapat pada buku ajar, maka buku ajar memiliki nilai tertinggi yaitu pada buku 5 sedangkan yang paling rendah yaitu pada buku 3 dan buku 4 .

Komponen STEM yang terakhir yaitu matematika. Komponen matematika yaitu kemampuan dalam menganalisis berbagai permasalahan maupun soal yang terdapat di dalam buku ajar. Soal yang ada pada buku ajar mengindikasikan soal yang mengharuskan siswa berfikir tingkat tinggi atau HOTS. Matematika juga berperan dalam menyampaikan ide secara kreatif dan dapat menginterpretasikan suatu data dengan baik.

Pada komponen matematika terdapat lima komponen pernyataan yang akan dianalisis. Hasil penilaian komponen matematika dapat diuraikan pada Gambar 4.

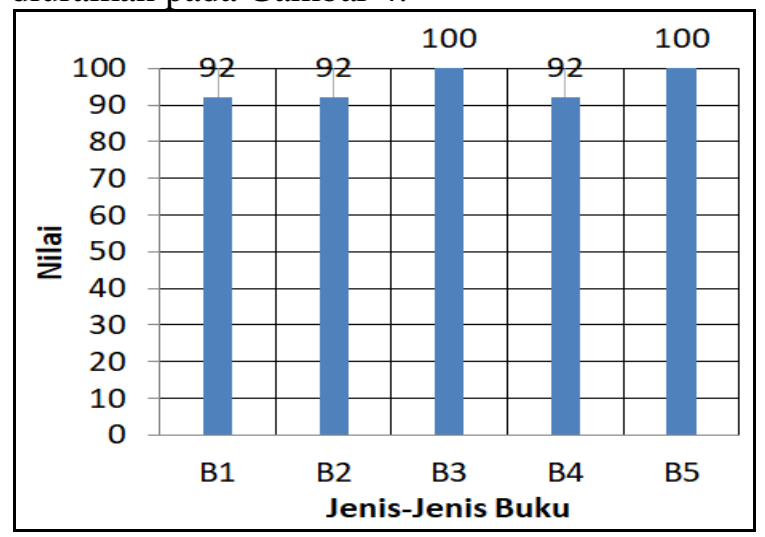

Gambar 4 Hasil Penilaian Komponen Matematika

Pada Gambar 4 dapat dilihat bahwa buku 1 memiliki nilai komponen matematika sebesar 92. Buku 2 memiliki nilai komponen matematika sebesar 92. Buku 3 memiliki nilai komponen matematika sebesar 100. Buku 4 memiliki nilai komponen matematika sebesar 92. Buku 5 memiliki nilai komponen matematika sebesar 100. Pada hasil penilaian komponen matematika buku 3 dan 5 memiliki nilai yang paling tinggi. Secara keseluruhan semua buku telah memenuhi komponen matematika untuk semua materi fisika SMA kelas X Semester 1.

Hasil secara keseluruhan komponen STEM pada masing-masing buku dapat dijabar kan pada Gambar 5. 


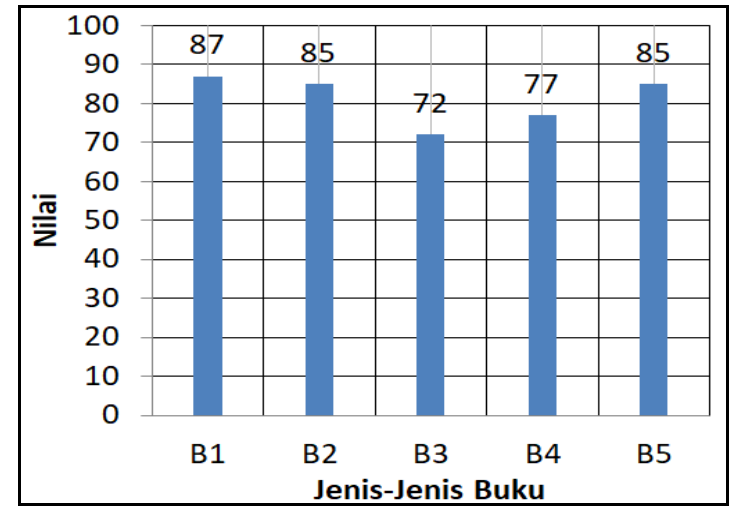

Gambar 5 Hasil Penilaian Komponen STEM

Untuk komponen STEM pada buku 1 memiliki nilai 88 , buku 2 sebesar 85 , buku 3 sebesar 72, buku 4 sebesar 77, dan buku 5 sebesar 85. Secara keseluruhan buku yang memuat STEM yang paling tinggi dimiliki oleh buku 1, dan buku yang memiliki komponen STEM paling rendah yaitu buku 3. Namun secara keseluruhan semua buku yang dianalisis telah memiliki komponen STEM.

\section{Pembahasan}

Salah satu perkembangan era revolusi pada bidang pendidikan yaitu adanya pembelajaran berbasis STEM. Pembelajaran ini memadukan antara sains, teknologi, rekayasa serta matematika dalam proses pemecahan masalah untuk mengembangkan kreativitas (Winarni et al., 2016). STEM mampu menciptakan sebuah sistem pembelajaran secara kohesif dan pembelajaran aktif karena keempat aspek dibutuhkan secara bersamaan untuk menyelesaikan masalah.

Berdasarkan analisis pada kelima buku fisika SMA Kelas X Semester 1 didapatkan hasil buku ajar yang memenuhi komponen STEM. Buku ajar yang memenuhi komponen STEM dengan baik yaitu pada buku 1. Buku yang belum memenuhi komponen STEM yaitu terdapat pada buku 3 .

Komponen STEM yang pertama yaitu sains. Pada komponen sains memuat stimulasi tentang alam sekitar, mengajak berpartisipasi aktif, merangsang siswa untuk bertanya dan mengajak siswa untuk menjelaskan sebuah peristiwa. Analisis yang dilakukan menunjukkan hasil hampir setiap buku memberikan stimulasi yang berkaitan tentang alam sekitar. Namun pada buku 3 hanya beberapa materi yang mengaitkan ke alam sekitar. Pada komponen sains buku 1 dan buku 2 telah memenuhi komponen sains dengan baik.

Ilmu sains merupakan ilmu yang mempelajari tentang dunia alam, tidak hanya ilmu fisika, di sini juga termasuk ilmu kimia dan biologi. Ilmu sains juga menerapkan prinsip dan konsep yang terkait dengan ilmu sains tersebut (Torlakson, 2014). Sains adalah pengetahuan yang mengikuti proses ilmiah yang selalu berkembang dan nantinya menghasilkan pengetahuan baru.

Penerapan sains di dalam buku ajar harus mengaitkan materi yang dipelajari dengan kehidupan sehari-hari (Permanasari, 2016). Selain menerapkan materi yang dipelajari sains juga berkaitan dengan kemampuan membaca dan memaknai suatu bacaan. Kemampuan sains juga dapat ditingkatkan dengan pengalaman, baik itu pengalaman yang didapat di dalam kelas, maupun di lingkungan sekitar. Melalui pengalaman ini siswa bisa mengaitkan apa yang telah mereka dapatkan di dalam kelas (teori) dan menyesuaikannya dengan pengalaman yang dialaminya dengan lingkungan sekitar.

Komponen STEM yang kedua yaitu teknologi. Pada teknologi memuat beberapa butir komponen yaitu memberikan informasi tentang perkembangan teknologi baru, informasi penggunaan teknologi dalam kehidupan seharihari, penggunaan software dalam pembelajaran serta buku ajar terhubung dengan internet. Dari kelima buku yang dianalisis buku yang memiliki komponen teknologi paling banyak yaitu terdapat pada buku 1. Sedangkan buku yang memiliki komponen teknologi paling rendah yaitu pada buku 3 .

Pada proses pembelajaran kita tidak luput dari perkembangan teknologi. Teknologi tidak bisa dipisahkan dengan sains. Pendidikan STEM dapat meningkatkan pemahaman siswa terhadap cara kerja dan pemahaman tentang cara penggunaan teknologi (Bybee, 2013). Proses pembelajaran akan berjalan secara lancar dan baik apabila guru siswa serta bahan ajar yang digunakan mengikuti perkembangan zaman. Hal ini sesuai dengan pendidikan STEM yang dimuat di dalam bahan ajar.

Contoh penerapan teknologi dalam buku ajar yaitu memasukan alamat web internet yang berhubungan dengan materi pembelajaran. Siswa tidak hanya terbatas mempelajari pelajaran melalui buku ajar saja. Dengan link tersebut siswa bisa mempelajari materi pembelajaran lebih luas. Contoh lainnya yaitu 
dengan memberikan informasi tentang perkembangan teknologi baru yang berkaitan dengan materi di dalam pembelajaran.

Komponen STEM yang ketiga yaitu rekayasa. Butir yang terdapat pada komponen rekayasa yaitu buku ajar memberikan tugas proyek, memadukan ilmu fisika dengan ilmu lainnya, dan memberikan solusi untuk permasalahan yang terkait materi yang akan dipelajari. Pada komponen rekayasa buku 5 memiliki nilai paling tinggi dibanding buku ajar lainnya. Sedangkan yang paling rendah yaitu pada buku 3 dan buku 4.

Rekayasa dapat berperan sebagai penghubung untuk mempelajari materi ilmu matematika dan sains secara bermakna (Shahali, et al., 2017). Salah satu penerapan rekayasa melaku kan praktikum. Melalui praktikum siswa bisa menerapkan dan membuktikan teori yang telah dipelajari di dalam kelas. Pelaksanaan prakti kum dapat memadukan ilmu sains (fisika) dengan ilmu lainnya seperti matematika. Penerapan rekayasa di dalam pembelajaran memiliki berbagai manfaat yaitu memberikan pemahaman dan kesesuaian antara teori dan praktik yang telah dipelajari, meningkatkan berpikir kreatif, siswa dapat membuat keputusan, dan memilih solusi yang terbaik untuk berbagai permasalahan yang ada.

Komponen STEM yang terakhir yaitu matematika. Pada komponen ini memuat soal yang mengharuskan siswa untuk menganalisis, buku ajar memuat ide kreatif dan buku ajar menuntun siswa untuk bisa menginterpretasikan data dengan benar. Selain itu buku ajar juga memuat soal yang membutuhkan cara berpikir tingkat tinggi atau HOTS. Dari semua buku ajar yang dianalisis semua buku telah memenuhi komponen matematika dengan baik.

Program pendidikan STEM yang berkualitas tinggi harus mencakup beberapa aspek yaitu pertama integrasi teknologi dan rekayasa ke dalam kurikulum sains dan matematika. Kedua melakukan penyelidikan ilmiah dan desain teknik, termasuk matematika dan sains. Ketiga pendekatan kolaboratif untuk belajar. Keempat memberikan sudut pandang global dan multiguna. Kelima memasukkan teknologi yang sesuai untuk meningkatkan pembelajaran (Kennedy \& Odell, 2014).

Tujuan pendidikan STEM yaitu dapat membawa siswa dalam memenuhi kemampuan abad ke-21. Kemampuan tersebut yaitu keterampilan belajar serta kemampuan memberikan inovasi. Kemampuan kedua yaitu berfikir kritis dan dapat menyelesaikan berbagai permasalah-an. Kemampuan berkreasi dalam mengguanakan teknologi dan mampu bekerjasama didalam ke lompok. Pembelajaran STEM mampu mengem bangkan kemampuan siswa yaitu kemampuan pengetahuan sikap dan keterampilan (Herber et al., 2016). Pada kompetensi pengetahuan mencakup kemampuan intelektual peserta didik. Kompetensi sikap adalah untuk mengukur tingkah laku peserta didik. Kompetensi keterampilan menekankan pada kemampuan kemampuan mengemukakan pendapat, berdiksusi, membuat laporan, serta dapat meng-komunikasikan hasil diskusi.

Dampak positif dari pembelajaran STEM yaitu pertama membuat siswa aktif dan kritis dalam proses pembelajaran. Kedua dapat meningkatkan motivasi siswa didalam proses belajar sains dan matematika. Ketiga dapat meningkatkan rasa ingin tahu siswa terhadap suatu peristiwa. Lalu yang terakhir siswa bisa mendapatkan pengalaman mengenai alam seki $\operatorname{tar}$ (Mayo, 2009).

Ada beberapa manfaat yang didapatkan dalam pemakaian STEM di dalam buku ajar yaitu membuat siswa menjadi mandiri dan berpikir kritis. Siswa dapat memecahkan masalah yang berkaitan dengan fisika serta tahu dengan perkembangan teknologi yang ada pada saat ini (Stohlman et al., 2012). Pelaksanaan STEM dapat meningkatkan minat dan motivasi siswa dalam belajar sehingga dapat meningkatkan prestasi siswa tidak hanya dalam bidang fisika namun dalam bidang ilmu lainnya. Oleh karena sangat penting untuk menerapkan STEM di dalam buku ajar agar dapat meningkatkan kemampuan berfikir kritis, kreatif dan mandiri.

\section{KESIMPULAN}

Hasil analisis dari ke lima buku ajar fisika SMA kelas X semester 1 di dapatkan hasil ratarata kesesuaian yang didapatkan untuk setiap buku yaitu pada buku 1 memiliki nilai 88 dengan kategori sangat sesuai dengan komponen STEM. Pada buku 2 memiliki nilai 85 dengan kategori sangat sesuai dengan komponen STEM. Pada buku 3 dengan nilai sebesar 72 dengan kategori sesuai dengan komponen STEM. Buku 4 dengan nilai sebesar 77 dengan kategori sesuai dengan komponen STEM. Terakhir, pada buku 5 dengan nilai 85 dengan kategori sangat sesuai dengan komponen STEM. 


\section{DAFTAR PUSTAKA}

Agustina, D., Kaniawati, I., \& Suwarma, I. R. (2017). Penerapan Pembelajaran Berba sis STEM (Science, Technology, Engineering, and Mathematics) untuk Meningkatkan Kemampuan Control Of Variable Siswa SMP pada Hukum Pascal. Prosiding Seminar Nasional Fisika (E-Journal) SNF2017. 6, pp. 1-6. Jakarta: Universitas Negeri Jakarta.

Asrizal, \& Dewi, W. S. (2018). Development Assistance of Integrated Science Instructional Material by Integrating Real World Context and Scientific Literacy on Science Teachers. Pelita Eksakta, 1(2), 113-120.

Asrizal, Amran, Ananda, \& Festiyed. (2018). Effectiveness of Adaptive Contextual Learning Model of Integrated Science by Integrating Digital Age Literacy on Grade VIII Students. IOP Conf. Series: Materials Science and Engineering (pp. 1-9). Padang: Universitas Negeri Padang.

Beers, S. Z. (2011). 21st Century Skills: Preparing Students for THEIR Future.

Budiharti, R., \& Devi, N. U. (2016). Efektivitas Model Pembelajaran Kooperatif Tipe The Power Of Two dalam Pembelajaran Fisika. Jurnal Materi dan Pembelajaran Fisika (JMPF), 6(1), 7-13.

Bybee, R. W. (2013, January 7). What is STEM Education. Retrieved from www. sciencemag.org.

Festiyed. (2018). Implementasi Model Pembe lajaran Trait Treatment Interaction (TTI) Menggunakan Multimedia Swish max 4.0. Natural Science Journal, 4(2), 636-650.

Festiyed, \& Murtiani. (2013). Meningkatkan Capaian Pembelajaran Mata Kuliah Komputer dalam Pembelajaran Fisika Melalui Implementasi Model Learning Cycle 5E (engagement, Exploration, Explanation, Elaboration, Evaluation). EKSAKTA, 2(1), 1-7.

Herber, Daniel, Deshmukh, A., Mitchell, M., \& Allison, J. (2016). Project-Based Curriculum for Teaching Analytical Design to Freshman Engineering Students via Reconfigurable Trebuchets. Education Sciences, 6(1), 7.
Kennedy, T., \& Odell, M. (2014). Engaging Students In STEM Education. Science Education International, 25(3), 258.

Masril, Hidayati, \& Darvina, Y. (2018). The Development of Virtual Laboratory Using ICT for Physics in Senior High School. IOP Conference Series: Materials Science and Engineering (pp. 1-8). Padang: Universitas Negeri Padang.

Mayo, M. J. (2009). Video Games; A Route to Large-Scale STEM Education. Science, 323, pp. 79-82.

Pangesti, K. I., Yulianti, D., \& Sugianto. (2017). Bahan Ajar Berbasis STEM (Science, Technology, Engineering, and Mathematics) untuk Meningkatkan Penguasa an Konsep Siswa SMA. Unnes Physics Education Journal, 6(3), 53-58.

Permanasari, A. (2016). STEM Education: Inovasi dalam Pembelajaran Sains. Prosiding Seminar Nasional Pendidikan Sains (SNPS) (pp. 24-34). Surakarta: Seminar Nasional Pendidikan Sains.

Rusman, M. (2017). Belajar dan Pembelajaran Berorientasi Standar Proses Pendidik an. Jakarta: PT Kharisma Putra Utama.

Shahali, E. H., Halim, L., Rasul, M. S., Osman, K., \& Zulkifeli, M. A. (2017). STEM Learning through Engineering Design: Impact on Middle Secondary Students' Interest towards STEM. EURASIA Journal of Mathematics Science and Technology Education, 13(5), 11891211.

Stohlman, M., Moore, T. J., \& Roehrig, G. H. (2012). Considerations for Teaching Integrated STEM Education. Journal of Pre-College Engineering Education Research (J-PEER), 2(1), 28-34.

Sugiyono. (2017). Metode Peneitian Kuantitatif, Kualitatif, dan $R \& D$. Bandung: Alfa beta.

Sukardi. (2004). Metodologi Penelitian Pendidik an: Kompetensi dan Praktiknya. Jakarta: Penerbit Bumi Aksara.

Torlakson, T. (2014). Innovate a Blueprint for Science, Technology, Engineering, and Mathematics in California Public Edu cation. California: Californians Dedi cated to Education Foundation.

Utami, I. S., Septiyanto, R. F., Wibowo, F. C., \& Suryana, A. (2017). Pengembangan 
STEM-A (Science, Teechnology, Engi neering, Mathematics, and Animation) Berbasis Kearifan Lokal dalam Pembe lajaran Fisika. Jurnal Ilmiah Pendidikan Fisika Al-BiRuNi, 6(1), 67-73.

Winarni, J., Zubaidah, S., \& H., S. (2016). STEM: Apa, Mengapa, dan Bagaimana.
Pros. Semnas Pend. IPA Pascasarjana UM. 1, pp. 976-984. Malang: Univer sitas Malang.

Yusuf, M. (2013). Metode Penelitian Kuanti tatif, Kualitatif dan Penelitian Gabung an. Padang: Kencana. 